\title{
PENGARUH HARGA DAN PELAYANAN TERHADAP KEPUTUSAN KONSUMEN BERBELANJA PADA MINI MARKET NAVVA DI KECAMATAN KEMBANGBAHU KABUPATEN LAMONGAN
}

\section{THE EFFECT OF PRICE AND SERVICE ON SHOPPING CONSUMER DECISIONS ON MINI MARKET NAVVA IN KEMBANGBAHU DISTRICT, LAMONGAN DISTRICT}

\author{
Kuswanto \\ Program Studi Pendidikan Ekonomi \\ Universitas PGRI Adi Buana Kampus Lamongan \\ mr.koes@yahoo.co.id
}

\begin{abstract}
ABSTRAK
Penelitian ini mempunyai tujuan untuk mengetahui 1) pengaruh harga secara parsial, 2) pengaruh pelayanan secara parsial, 3) Pengaruh simultan harga dan pelayanan terhadap keputusan berbelanja pada Mini Market Navva di Kecamatan Kembangbahu Kabupaten Lamongan. Jenis penelitian ini adalah penelitian deskriptif kuantitatif. Subjek dalam penelitian ini adalah konsumen Mini Market Navva, sedangkan objek dalam penelitian ini adalah pengaruh harga dan pelayanan terhadap keputusan berbelanja di Mini Market Navva di Kecamatan Kembangbahu Kabupaten Lamongan. Metode pengumpulan data yang digunakan adalah kuesioner. Teknik analisis data yang digunakan yaitu analisis kuantitatif dengan menggunakan analisis uji asumsi klasik, dan uji statistik yaitu uji t, uji F, analisis regresi linier berganda dan analisis koefisien determinasi berganda dengan menggunakan bantuan program SPSS Statistics 18. Hasil penelitian menunjukkan bahwa secara parsial variabel harga berpengaruh positif dan signifikan terhadap keputusan berbelanja di mini market Navva di Kecamatan Kembangbahu Kabupaten Lamongan sebesar 28,7\%. Variabel pelayanan berpengaruh positif dan signifikan terhadap keputusan berbelanja sebesar 77,1\%. Pengaruh harga dan pelayanan secara simultan berpengaruh positif dan signifikan terhadap keputusan berbelanja di mini market Navva di Kecamatan Kembangbahu Kabupaten Lamongan sebesar 76,8 \%

Kata Kunci: Harga, Pelayanan, Keputusan Berbelanja
\end{abstract}

\section{ABSTRACT}

This study aims to determine 1) the effect of price partially, 2) the effect of partial service, 3) The simultaneous influence of price and service on shopping decisions at the Navva Mini Market in Kembangbahu District, Lamongan Regency. this type of research is quantitative descriptive research. The subjects in this study were consumers of the Navva Mini Market, while the object in this study was the effect of prices and services on Shopping Decisions at the Navva Mini Market in Kembangbahu District, Lamongan Regency. The data collection method used was a questionnaire. Data analysis technique used is quantitative analysis using classical assumption test analysis, and statistical tests are t test, $F$ test, multiple 
P-ISSN 2580 - 7781

E-ISSN 2615 - 3238

linear regression analysis and coefficient of multiple determination analysis using SPSS Statistics 18. The results of the study indicate that partially the price variable positive and significant effect on shopping decisions at the Navva mini market in Kembangbahu District, Lamongan Regency by 28.7\%. Service variables have a positive and significant effect on shopping decisions of $77.1 \%$. The simultaneous influence of price and service has a positive and significant effect on shopping decisions at the Navva mini market in Kembangbahu District, Lamongan Regency by $76.8 \%$

Keywords: Price, Service, Shopping Decision

\section{PENDAHULUAN}

Pembangunan di Indonesia yang semakin berkembang dan pertumbuhan ekonomi serta industri telah banyak mengalami perkembangan yang sangat cepat dibandingkan dengan masa-masa sebelumnya. Hal ini bisa dilihat dari keterlibatan pihak produsen yang semakin bertambah banyak dalam pemenuhan dan keinginan konsumen sehingga sebagai tujuan utama, sehingga perlunya setiap perusahaan untuk berorientasi pada konsumen. Barang atau jasa yang mempunyai nilai lebih tinggi harus bisa diberikan perusahaan kepada konsumen, harga lebih murah, dengan mutu yang lebih baik, fasilitas yang memadai dan pelayanan yang lebih baik dari pada pesaingnya. Perusahaan akan mengalami kekalahan dalam bersaing jika Dalam dunia perdagangan tidak dapat menyusun strategi bisnis dan strategi pemasaran yang tepat,dimana untuk mempertahankan kelangsungan hidupnya, para pengusaha harus melakukan salah satu kegiatan pokok yaitu menerapkan strategi pemasaran untuk berkembang dan untuk memperoleh profit atau keuntungan yang besar. Dalam pemasaran salah satu aspek pentingnya adalah mendorong calon konsumen untuk membeli, yang terpenting adalah perusahaan harus dapat menciptakan customer value yang lebih tinggi dibandingkan dengan pesaing, hal itu dilakukan dalam upaya memberikan kepuasan kepada pelanggan.

Dalam menjalankan usahanya, setiap perusahaan pada umumnya menginginkan keberhasilan. Oleh karena itu, suatu perusahaan tidak dapat bertahan tanpaadanya transaksi pembelian. Perusahaan harus dapat memasarkan barang atau jasa yang dihasilkan kepada konsumen agar perusahaan dapat terus bertahan dan bersaing dengan perusahaan lain. 
P-ISSN 2580 - 7781

E-ISSN 2615 - 3238

Pemasaran telah mengembangkan sebuah pengertian kepada konsumen, dimana pada saat membeli sesuatu, konsumen telah membuat sebuah keputusan dan telah jauh mendalami bermacam-macam hal yang bisa mempengaruhi konsumen, tujuan diadakannya pemasaran adalah mempengaruhi pembeli untuk bersedia membeli barang dan jasa perusahaan padasaat mereka membutuhkan. Menurut Swastha dan Handoko (2000:111) faktor-faktor yang mempengaruhi keputusan pembelian berbeda-beda untuk masing-masing konsumen di samping produk yang dibeli dan saat membelinya berbeda. Faktor-faktor tersebut adalah, pelayanan yang optimal, lokasi penjualyang strategis, kemampuan tenaga penjualnya, tingkat harga, iklan dan promosi, penggolongan barang. Faktor harga dan pelayanan berpengaruh besar untuk menentukan proses dimana pembeli/konsumen akan berbelanja. Dalam berbelanja, konsumen biasanya membutuhkan pertimbangan yang dapat menguntungkan dan dan benar-benar mendukung seperti faktor harga dan pelayanan.

Harga adalah beberapa nilai uang yang harus dibayarkan oleh konsumen kepada penjual untuk memperoleh produk atau jasa tersebut. Satu-satunya unsur bauran dalam pemasaran yang menghasilkan pendapatan penjualan adalah harga karena unsur yang lain adalah mengeluarkan biaya. Basu Swasta dan Ibnu Sukotjo (1998 : 211) : Harga adalah beberapa nilai uang (ditambah beberapa barang kalau mungkin) yang dibutuhkan untuk mendapatkan sejumlah kombinasi dari barang beserta pelayanannya.

Suatu perusahaan yang mampu memberikan pelayanan yang baik kepada pelanggan akan membuat citra positif bagi perusahaan. Untuk mendorong minat konsumen agar kembali menggunakan jasa tersebut maka perlu adanya pelayanan yang baik sehingga tercipta loyalitas. Perusahaan yang menjualkan pelayanan jasa kepada konsumen bisa diartikan bahwa perusahaan menjualkan produknya dalam bentuk kepercayaan.

Perusahaan bisa dikatakan berhasil jika perusahaan tersebut bisa memberikan pelayanan yang terbaik kepada konsumen. Dan ketika perusahaan sudah mendapatkan brand yang baik dimata konsumen karena pelayanan yang 
P-ISSN 2580 - 7781

E-ISSN 2615 - 3238

memuaskan, maka perusahaan tersebut berhasil memasarkan produk/jasanya kepada konsumen. Pelayanan yang dimaksud termasuk dari pelayanan suatu saat menawarkan produk/jasa, pelayanan ketika memberikan pelayanan/jasa, pelayanan terhadap resiko yang terjadi saat memberikan pelayanan/jasa dan pelayanan lain sebagainya.

\section{METODE PENELITIAN}

\section{Definisi Operasional Variabel dan Pengukuran}

Dalam penelitian ini menggunakan beberapa Variabel yaitu :

a. Variabel Bebas

1. Harga (X1) : Harga merupakanbeberapa uang yang harus dibayarkan oleh pembeli kepada penjual untuk memperoleh produk atau jasa.

2. Pelayanan (X2) : Kemampuan para staf atau karyawan dalam memberikan pelayanan kepada konsumen.

b. Variabel Terikat

Keputusan Konsumen (Y) adalah pilihan konsumen untuk menggunakan produk atau jasa yang ditawarkan.

\section{Teknik Pengumpulan Data}

Proses pengumpulan data dalam peneilitian ini, menggunakan beberapa teknik :

a. Observasi

Yaitu teknik pengumpulan data dengan cara mengamati secara langsung konsumen yang menjadi objek penelitian. Pengamatan ini dilakukan secara langsung pada mini market navva

b. Wawancara, yaitu teknik pengumpulan data dengan cara melakukan tanya jawab dengan pengelola mini market dan konsumen navva untuk mendapatkan data yang akurat. 
P-ISSN 2580 - 7781

E-ISSN 2615 - 3238

c. Kuesioner yaitu dengan mengedarkan daftar pertanyaan yang berkaitan dengan lokasi dan harga dalam keputusan konsumen membeli produk di mini market navva.

\section{Populasi dan Sampel}

Menurut Sugiono (2010 : 12) Untuk generalisasi atau hasil penelitian perlu ditetapkan besarnya sampel yang digunakan tergantung banyak faktor antara lain biaya, tenaga dan waktu, pendekatan secara metode ilmiah besar sampel tergantung kepada apakah populasi terbatas atau tidak terbatas, Populasi adalah obyek suatu penelitian dalam hal ini adalah konsumen mini market navva di kecamatan Kembangbahu diambil sebanyak 50 orang konsumen merupakan sampel yang diambil secara acak.

\section{Metode Analisa}

Untuk menguji kebenaran dari hipotesis yang diajukan, maka akan diuji dengan regresi linier berganda dengan menggunakan program SPSS sebagai berikut:

$\mathrm{Y}=\mathrm{a}+\mathrm{b} 1 \mathrm{x} 1+\mathrm{b} 2 \mathrm{x} 2+\mathrm{e}($ Sugiono , 2010)

Keterangan :

$\mathrm{Y} \quad=$ Keputusan Konsumen

$\mathrm{X} 1=$ Harga

$\mathrm{X} 2$ = Pelayanan

a $\quad=$ Konstanta

$\mathrm{b} \quad=$ Koefisien regresi

e $\quad=$ Standart error

\section{HASIL PENELITIAN DAN PEMBAHASAN}

Untuk mengetahui hubungan serta besarnya pengaruh yang diberikan lokasi terhadap terikat, sedangkan untuk uji $\mathrm{F}$ digunakan untuk menguji signifikansi persamaan garis regresi secara keseluruhan atau untuk menguji 
P-ISSN 2580 - 7781

E-ISSN 2615 - 3238

pengaruh variabel bebas secara bersama-sama terhadap variabel terikat, dalam hal ini untuk mengetahui pengaruh harga dan pelayanan terhadap keputusan konsumen berbelanja di mini market Navva di Kecamatan Kembangbahu, analisis regresi linier berganda untuk mengetahui hubungan antara variabel bebas dengan variabel terikat, yaitu lokasi (X1), harga (X2) terhadap keputusan berbelanja (Y) selain itu juga ingin mengetahui sejauh mana besarnya pengaruh antara variabelvariabel bebas dengan variabel terikatnya baik secara bersama-sama maupun secara parsial. Analisis Koefisien Determinasi Berganda (R2) untuk mengukur tingkat ketepatan atau kecocokan (goodness of fit) dari garis regresi, yaitu mengukur besarnya proporsi sumbangan $\mathrm{X} 1$ dan $\mathrm{X} 2$ terhadap variasi (naik turunnya) Y secara bersama-sama.

Keputusan berbelanja akan dijelaskan dengan melihat hasil perhitungan StatisticalProgram Social Scence (SPSS). Adapun pengaruh lokasi terhadap keputusan berbelanja nampak pada tabel dibawah ini

Coefficients $^{a}$

\begin{tabular}{|c|c|c|c|c|c|c|}
\hline \multirow{2}{*}{\multicolumn{2}{|c|}{ Model }} & \multicolumn{2}{|c|}{ Unstandardized Coefficients } & \multirow{2}{*}{$\begin{array}{c}\begin{array}{c}\text { Standardized } \\
\text { Coefficients }\end{array} \\
\text { Beta }\end{array}$} & \multirow[b]{2}{*}{$\mathrm{t}$} & \multirow[b]{2}{*}{ Sig. } \\
\hline & & $\mathrm{B}$ & Std. Error & & & \\
\hline \multirow[t]{3}{*}{1} & (Constant) & $-1,161$ & 1,544 & & -.752 & .456 \\
\hline & Harga &, 156 &, 021 &, 287 & 7,324 &, 000 \\
\hline & Pelayanan &, 958 &, 049 &, 771 & 19,654 &, 000 \\
\hline
\end{tabular}

Dilihat dari hasil analisis pada tabel diatas uji t terhadap variabel lokasi X1 didapatkan $\mathrm{t}$ hitung sebesar 7,324 dengan probabilitas t sebesar 0,000. Karena thitung > ttabel $(7,324>1,668)$ atau signifikansi t lebih kecil dari 5\% $(0,000<0,05)$ maka secara parsial variabel Lokasi X1 berpengaruh signifikan terhadap variabel keputusan berbelanja Y. Besarnya pengaruh parsial Harga X1 terhadap Keputusan Berbelanja Y dilihat dari nilai standardized coefficients beta sebesar 0,287 $(28.7 \%)$.

Melihat hasil SPSS yang berada pada tabel diatas uji t terhadap variabel Pelayanan (X2) didapatkan nilai thitung sebesar 19.654 dengan probabilitas 0,000, dikarenakan thitung $>$ ttabel $(19.654>1,668)$ atau signifikansi t lebih kecil dari 5\% 
P-ISSN 2580 - 7781

E-ISSN 2615 - 3238

$(0,000<0,05)$, maka Data yang dikolerasikan dalam penelitian ini adalah data tentang variabel Harga (X1), Pelayanan (X2) yang secara bersama sama secara parsial variabel Pelayanan (X2) berpengaruh signifikan terhadap keputusan berbelanja Y. besarnya pengaruh Harga (X1) terhadap keputusan berbelanja Y dilihat dari nilai standardized coefficients sebesar $0,771(77,1 \%) 2$ dengan variabel Keputusan Berbelanja (Y).

ANOVA ${ }^{\mathrm{b}}$

\begin{tabular}{|rl|r|r|r|r|r|}
\hline Model & & \multicolumn{1}{c|}{$\begin{array}{c}\text { Sum of } \\
\text { Squares }\end{array}$} & df & Mean Square & \multicolumn{1}{c|}{$\mathrm{F}$} & Sig. \\
\hline 1 & Regression & 573,899 & 2 & 286,950 & 518,306 &, $000^{\text {a }}$ \\
& Residual & 26,021 & 47 &, 554 & & \\
& Total & 599,920 & 49 & & & \\
\end{tabular}

a. Predictors: (Constant), Pelayanan, Harga

b. Dependent Variable: Keputusan_Konsumen

Dilihat dari tabel diatas hasil analisis SPSS menunjukkan nilai $\mathrm{F}=518,306$ lebih besar dari nilai $\mathrm{F}$ tabelhitung $=4,00$ atau $\mathrm{p} \_$value $=0,000<0,05$ dapat disimpulkan bahwa Ha diterima dan Ho ditolak dengan demikian Harga dan Pelayanan secara simultan berpengaruh signifikan terhadap Keputusan Berbelanja. Untuk mengetahui besarnya pengaruh Harga dan Pelayanan Terhadap keputusan berbelanja digunakan analisis koefisien determinasi R2 itu dapat dilihat dari tabel SPSS dibawah ini.

\begin{tabular}{|c|c|c|c|c|c|c|c|c|c|}
\hline \multicolumn{10}{|c|}{ Model Summary } \\
\hline \multirow[t]{2}{*}{ Model } & \multirow[b]{2}{*}{$\mathrm{R}$} & \multirow[b]{2}{*}{ R Square } & \multirow[b]{2}{*}{$\begin{array}{l}\text { Adjusted R } \\
\text { Square }\end{array}$} & \multirow[b]{2}{*}{$\begin{array}{l}\text { Std. Error of } \\
\text { the Estimate }\end{array}$} & \multicolumn{5}{|c|}{ Change Statistics } \\
\hline & & & & & $\begin{array}{l}\text { R Square } \\
\text { Change }\end{array}$ & F Change & df1 & $\mathrm{d} f 2$ & Sig. F Change \\
\hline 1 & $978^{\mathrm{a}}$ & 957 & .955 & 7,744 & .957 & 518,306 & 2 & 47 &, 000 \\
\hline
\end{tabular}

Dari tabel diatas besarnya pengaruh harga dan pelayanan terhadap keputusan konsumen berbelanja secara simultan sebesar 0,955 atau sebesar 95,5\%. 
P-ISSN 2580 - 7781

E-ISSN 2615 - 3238

\section{KESIMPULAN}

Dari pengujian dan analisis yang dilakukan, maka kesimpulan dari penelitian ini adalah sebagai berikut :

1. Ada pengaruh positif dan signifikan secara parsial harga dan kualitas pelayanan terhadap keputusan pembelian konsumen.

2. Ada pengaruh positif dan sangat berarti secara bersamaan antara harga dan kualitas pelayanan terhadap keputusan pembelian konsumen.

\section{DAFTAR PUSTAKA}

Arikunto. 2002. Prosedur Penelitian Suatu Pendekatan Praktik. Jakarta: Rineka Cipta

Assauri.1996. Manajemen PemasaranDasar konsep Dan Strategi. Jakarta: Rajawali Press

------. 2004. Manajemen Pemasaran Dasar Konsep Dan Strategi. Jakarta:Rajawali Press

Azwar.2003. Metodelogi Penelitian.Jakarta: Binarupa aksara

Bambang P. dan Lina, M. 2005.MetodePenelitian Kuantitatif. Jakarta: PT.Raja Grafndo Persada

Ferdinand, Augusty. 2006. MetodePenelitian Manajeme. Semarang: Universitas Diponegoro

Ghozali, Imam. 2009. Ekonometrika Semarang: Universitas Diponegoro

Gitosudrmo. 2012. Manajemen Pemasaran. Yogyakarta: BPFE

Luthfia, Widha Emil. 2012. Analisis Pengaruh Kualitas Produk, KualitasLayanan, dan Harga TerhadapKeputusan Pembelian pada CoffeeShop Kofisyop Tembalang. Skripsi (tidak diterbitkan). Semarang: Fakultas Ekonomika dan Bisnis Universitas Diponegoro

Sugiyono. 2000. Metode Penelitian Bisnis(Pendekatan Kuantitatif Kualitatif dan $R \& D$ ). Bandung: Alfabeta

Purana, Pradana Jaka. 2011. Analisis Pengaruh Produk, Harga, dan Lokasi Terhadap Keputusan Pembelian.Skripsi (tidak diterbitkan). Semarang: Fakultas Ekonomi Universitas Diponegoro 